\title{
Authenticity and the Rhetoric of "Selling" on Social Media: A Role-writing Assignment Set
}

\author{
Jessica McCaughey* \\ $06 / 20 / 2018^{\dagger}$
}

\begin{abstract}
Rooted in a hybrid, themed, first-year writing course titled Please Like Us: Selling with Social Media and drawing on the disciplines of business, marketing, and writing studies, the two sequenced assignments explored here rely upon role-playing and "role-writing" for specific outside professional audiences. A semester-long blog project serves as a jumping off point for a researched, multi-disciplinary social media marketing proposal, providing students with the chance to examine social media in both rhetorical and professional terms. The accompanying article explores these assignments in the context of "authenticity" and with an eye toward not only principles of writing pedagogy, but also the transfer of knowledge and process between academic and professional writing.
\end{abstract}

The two writing assignments exhibited here, a semester-long blog project and a social media marketing proposal, were designed for a four-credit, themed, first-year writing (FYW) course titled Please Like Us: Selling with Social Media at a private, urban, research university. My work in developing both the course and these assignments was a response to an issue that is specific to multi-disciplinary writing programs like mine: We were heavy with humanities-focused themes, and our business students wanted courses that related to both their interests and their future professional lives. And yet, four years into teaching this course, I have students from all different disciplines enroll in the course. I have come to realize that this perhaps unexpected type of intellectual work genuinely engages a range of students and teaches important skills and ways of thinking that are both within the realm of typical FYW objectives and beyond them.

This two-part project allows students to explore and analyze the ways companies and

\footnotetext{
${ }^{*}$ University Writing Program, The George Washington University, jessmcc@gwu.edu. Copyright 2018 Jessica McCaughey. This work is licensed under a Creative Commons Attribution-NonCommercial 4.0 International License (http://creativecommons.org/licenses/by-nc/4.0/).

${ }^{\dagger}$ Submitted, 03/01/17; Accepted, 11/20/2017.
} 
public figures strategize rhetorically to reach a target audience and achieve specific goals. The assignments are sequenced, meaning the writing that students develop in the early assignments serve as essential preparation and, at times, elements of a draft, for the larger, second project. As a class, we consider issues crucial to any modern first-year composition course, including the writing process, research, critical thinking and analysis, feedback and revision, rhetorical principles, collaborative writing, and multi-modality. And yet, these issues are framed in the context of a "professional" writing genre: in this case, the marketing proposal.

This perhaps unexpected genre for FYW turns out to be a surprisingly ripe genre for so many of the complex skills we aim to teach. The course aims to allow students to gain a set of crucial, if expected, skills and it also allows them to build for themselves a sturdy process for adapting to new writing circumstances. These learning objectives mean that students will both understand that writing shifts with the rhetorical situation, or the "context in which speakers or writers create rhetorical discourse" (Bitzer, 1968), but also that there are questions to be asked, ways of thinking, and strategies for drafting and revision that create more of a level playing field when it comes to approaching new writing tasks, whether that is a lab report in a biology class or a specialized report in the first month in a new job. Students have what many would consider an essential opportunity to ultimately transition their writing, eventually, into the work world as they "explore professional discourse in rhetorical terms" (Shaver, 2011).

Students enter this class as first-year students, and they quickly take on new, imagined personas as social media marketing consultants with an interest and a developing expertise in a specific industry. Some students choose industries that hold some professional interest for them (venture capital firms or lobbying groups, for instance), and others focus on those that could be described as more personally engaging (a set of favorite fashion bloggers or local restaurants). We spend the first week of class defining the work and this new role through discussions and brief video interviews with social media consultants. We also consider the intersections and divergences of academic and professional writing.

Students then narrow their focus even further, choosing three individuals or organizations in a field who are active, though not necessary effective, on social media, and tracking them on every platform they use for marketing and branding, advocacy, and/or fundraising. Students create a weekly blog on which they monitor and rhetorically analyze the work each company does, placing particular attention to the ways in which the text is targeted (or not) for a specific audience and, often, multiple purposes. Students examine and analyze alphabetic-text posts as well as visual and multi-modal outreach from their chosen organizations. In determining whether the organization or individual has had a "successful" week on social media, students consider rhetorical appeals, visual rhetoric, and language. They also consider audience engagement in such forms of "likes" and retweets, but to a lesser degree. In this early stage of their blogs, students acquire feedback from both their peers (grouped as usefully as possible by industry or rhetorical connections) and from me. 
I chose the blog genre first because it offers a way for students to publically inhabit this persona of a social media marketing consultant. In a different kind of class perhaps these rhetorical analyses might take the form of a weekly journal or some similar low-stakes assignment, but I like the blogs because they reinforce this role. Secondly, the form straddles the line between the professional (we often encounter "professional" blogs online, and in fact as a class we seek them out as models) and the casual. In a class in which I am working hard to teach students the ways in which writing shifts from one context to the next, asking them to adapt concepts and writing from one set form (the blog) to a more formal genre down the line (the proposal) allows them to see this adaptation in action and to practice it.

As the semester progresses, students perform several more formal assignments, and, at mid-semester, the blog leads us to the final project. The writing that students have been doing on their blogs becomes a key starting point, and much of that work is "repurposed" for the final project, which gives us another great opportunity to talk about genre conventions and rhetorical choices. Students are asked to decide which of their three organizations is the "least effective," based on their analyses, and then they are tasked with preparing a comprehensive social media marketing proposal for that organization. Although the company/individual has not, of course, actually put out a call for social media proposals, the prompt is framed as a Call for Proposals (CFP). At this stage, we pause to consider both this likely new-to-them professional genre and their continued "public," if imagined, persona as a consultant. We read both professional and former student proposal models, and we talk extensively about the kinds of questions that can help us to tackle other unfamiliar genres.

We also talk about another likely unfamiliar hurdle: The assignment asks students to cross traditional disciplinary research guidelines. It is not a history paper in a history class, nor a psychology paper in a psychology class. It is a "professional" work in a writing class, and the overarching understanding students have of their research constraints is that there are few. They are asked to determine what kinds of research and what blend of disciplines will adequately support the arguments they are attempting to make. For all of the students, there is some scholarly research in business and marketing, particularly digital marketing. In addition, many students turn to psychology researchers as they dig into the psychology of the specific audience that "their" organization is attempting to reach. Or they examine decision sciences or consumer psychology as they consider how a particular audience might make a choice to support a given organization. And, of course, they look to the discipline that most closely involves or aligns with their industry. As an example, a student writing a proposal for an art museum would also seek out research in museum studies and, potentially, in art history. For some students, this might mean research in political science or agriculture; for others, it might be technology or journalism. What I like about this aspect of the project is that it does that tricky work of showing why academic research can be relevant/important to "life" outside of the university.

As students begin to understand their chosen industry and the research that will be useful 
to them, we enter into what Bass and Elmendorf (2018) define as a "social pedagogy"one that utilizes "design approaches for teaching and learning that engage students" with as authentic a reader as possible. We know that students struggle to make the shift from writing in their college classes to writing in the workplace, and research consistently shows that the more "authentic" and varied the situation we place students in, the more likely it is that the transfer of writing skills will occur. In their 2011 article "Professional Writing in the English Classroom," Jonathan Bush \& Lea Zuidema state:

Students who write within authentic contexts... are immersed in meaningful composing. They are also engaged in higher-order thinking, decision making, and genre learning. They are creating complex products using the same processes that professionals do. They are not simply reiterating forms and template; they are creating their own idea of what the genre is, based on their understanding of the audience, situation, and purpose of the task (Bush \& Zuidema, 2011).

Such assignments are typical in business, but somewhat less so in writing studies, although they are becoming more common as we see writing studies research about how well this encourages transfer ("The Elon Statement on Writing Transfer" 2017). I will admit I make a hard sell about the value of performing such writing (professional writing) for part of our semester together - and I really believe in its value. As a teacher, I am particularly interested in authenticity and its role in the transfer of writing skills to both upper-level courses and to the professional realm, and I have found that this assignment sequence serves as a useful and engaging stepping stone toward "transfer skills" like asking questions about rhetorical situation and genre and in offering authentic writing contexts.

For this class, authenticity means a real-world scenario, writing to someone other than the professor and classmates, and encountering professional writing genres and challenges. We know that in the workplace, there are huge variations in genre (Shaver, 2011). Reports look different from one department to the next, let alone between separate organizations. To that end, I am working to teach these "real-world," post-college genres, while also giving students the strategies to shift or adapt their writing to fit new constraints and requirements, whether that is in another classroom or in their future workplace. Further, in addressing authenticity, we consider the idea of the author's persona and voice, as well as expertise, as students are inhabiting a different kind of writing and therefore becoming different kinds of writers. Students will be, in their professional lives, asked to write on behalf of others. However foreign this consultant persona seems, the students recognize (though classroom discussion and readings) that even in "authentic" situations, we may not be writing as our "authentic" selves - meaning that they will likely have to write as the organization they work for down the line, either as a representative or as the actual voice of the company, such as in marketing or web content.

And yet, of course, with the "authenticity" of the professional world comes a variation on 
academic work. One of the limits of this assignment - and something I have struggled with since its first iteration - is that I am not teaching a traditional academic research paper in this first-year writing course. To counterbalance that, it has been crucial that we talk in the classroom about the concept within transfer studies of boundary crossing, as Terttu Tuomi-Gröhn and Yrjö Engeström (2003) refer to it. This act "involves encountering difference, entering into territory in which we are unfamiliar and, to some significant extent therefore, unqualified." As anyone who has attempted such transfer knows, this requires "significant cognitive retooling" (Tuomi-Gröhn \& Engeström, 2003, p. 4).

This focus on boundary crossing allows me to stress not only the process of writing and revising (as we all do in any writing assignment), but also the act of managing the process. One of the key benefits to this complex, multi-section (and, thus, multi-argument) researched proposal is that it requires students to ultimately manage a project that looks very much like a real-world work project. We talk through such issues, asking questions such as: How would you start to figure this out? Where would you look for samples? How would you evaluate those samples? Tim Krause wrote about this in an article in the The Writing Instructor called "Using Simulation to Teach Project Management in the Professional Writing Classroom," (2010) in which he states:

When we tell students that writing assignments have constraints that include page length ... we assume that defining the scope ... involved in completing a project frees our students to focus on what really matters: the process of composing. We might also argue that doing so simplifies the overall process so that it doesn't overwhelm less-experienced writers. Nevertheless, these decisions privilege one part of the writing process: composing, over managing the process itself. To be successful workplace writers, students need experience with both. (Krause, 2010)

Asking students to conceive of their written work in this way-to manage a project in a professional context - teaches them the kinds of critical thinking (and working) skills that we all say we want them to have when they leave the university.

Of course, they are not professionals at this stage, and therefore it can be a struggle in the beginning for students to trust their ability to offer critiques of often well-known organizations or individuals. I can say, though, that by the time they are ready to begin the proposal, we are able to look back together on the usually complicated and successful work they have done on their blogs, and this often provides some degree of confidence. Further, as they become more comfortable in this role, my students begin to see that as "digital natives" they do usually possess a social media literacy that is lacking in even some of the most established companies. It is worth noting that this background is perhaps to some extent specific to the student population at my private university, where most of the students have had access to a variety of technologies throughout their lives, and where, unfortunately, I teach very few non-traditional students. And yet, I still believe that many other students in various higher education contexts will, as my 
students have, find themselves perhaps more adept at these social technologies than the organizations they are studying. It is often a joy for them, upon realizing this, to examine rhetorically why something they know "works" actually works.

The results are truly impressive. The proposals are substantial in size and depth, and they achieve an impressive level of professionalism. I find that if a student has been working on a topic all semester, they are not only better able to provide deeper analysis, but by and large they are also more invested in the final version of the project. After somewhere in the range of 14 weeks of work, even a typo infuriates them. My expectations for quality are quite high, considering the time we spend on the projects, both in the early blog-form drafts and through to multiple drafts of each piece of the proposal. Further, while it is not required, many students opt to send the proposal to the company they have developed it for, and I believe that this is an added motivation. A surprising number have gotten personalized, positive responses back. Two of them have been offered internships at the organizations they wrote about. A perhaps less important, but still useful, feature of this assignment is that it provides students with a "professional" writing sample, often called for in internship and job applications, but not, I have learned, often something students are able to produce easily or comfortably. I talk about these options early in the semester and students have expressed to me that they have served as added motivations for producing their highest possible quality of work.

But of course, the most exciting things to me about the assignment are not the internships nor the writing samples; it is the fact that I believe it genuinely teaches students about argument and about adapting their writing for various professional contexts. Whether they end up in Jordan managing developmental aid projects or running for office, understanding the concept of a rhetorical situation and being able to both ask questions and adapt based on the answers to those questions will be central to my students' future professional writing lives. And they learn those skills and abilities through this complex assignment sequence. Whether they have written about the social media of Taylor Swift or Hillary Clinton, a refugee aid organization or brand of cookies, students have not just made the case for their proposal to be "chosen" by the "client," but they have also come to understand, through questioning and writing, the ways in which specific social media posts might persuade buyers, or philanthropists, or readers. They are arguing in their writing about what makes an effective argument, and this ability to identify and create strong, cohesive, supported arguments is one the most important skills of any college graduate. Although this assignment set might be viewed as specific to a very particular kind of class, I believe that with adjustments and scaling, it is the kind of work many professors could and should engage their students in, whether the focus is on marketing and business, rhetoric, communications, or some other area. 


\section{The Assignment: Social Media Assignments}

See the Supplementary Files for this article at thepromptjournal.com for a PDF facsimile of the original formatting of this assignment. ${ }^{1}$

\section{Assignment Part 1: Semester Blog Project}

In this class you'll wear multiple hats. First, as all University Writing students do, you'll take on the roles of scholar and critic, in our case examining the rhetoric of social media as it is used for selling and promoting products, organizations, people, and causes. Your other role, however, is unique to this class: Social Media Expert/For-Hire Consultant. Through this blog, you will both analyze and actively engage with social media writing in your chosen field or industry as you consider the rhetorical situation as it applies both to the marketing efforts of organizations and to your own academic work.

\section{Your Area of Expertise}

In this new role, you will choose a related group of three individuals, companies, movements, or organizations that are active in social media, and you will track, analyze, and critique their marketing or promotion efforts over the course of the semester. For instance, you might choose to examine a group of cosmetic companies or a chain of coffee shops. Those interested in policy and politics might follow individual politicians or lobbying groups. You could follow churches or food brands, or you could track celebrities working to create and maintain a brand or authors promoting new books, or perhaps sports teams or airlines, venture capital firms or yoga studios. You will post analyses and comparisons of these campaigns, along with related posts, on your individual blog.

In choosing, you should consider the following qualifications: The organizations/causes/people you choose to follow must have an active (though not necessarily effective!) social media presence. This means that you must demonstrate that each of campaigns you're tracking uses at least two forms of social media (FB and Twitter, for example, or they have YouTube channel and they utilize Pinterest) at least twice weekly. Further, you should consider variety in your choices. While the organizations you track must be related, they should be diverse within an industry, as we are going to be comparing and contrasting. For instance, following Coke, Pepsi, and Mountain Dew (three huge brands with similar budgets, with very similar target buyers) would likely not yield analysis that furthers the larger dialogue. However, an examination of Pepsi alongside of World Classics (a European soda company), and a small, regional organic soda producer would likely have more at stake and allow you to explore with more nuance. 


\section{The Blog}

Your audience for the blog is organizations or companies in your chosen field or industry who are looking to better understand social media. A secondary audience is other social media consultants. The rhetorical choices you make in writing your blog will be dependent on these audiences, but also on other factors. For instance, tone and level of formality will vary based upon audience, of course, but also upon your subject. If you are studying social media in the world of stand-up comedy or reality television, your tone and level of formality will likely be quite different from a classmate who is working in the hedge fund or political realm. (Note: In week one, you will write a short post about the rhetorical situation of your blog).

As experts in the rhetoric of selling with social media, in addition to exploring the campaigns of your three chosen organizations, you will use your blog to respond to the ideas of other experts in the field and analyze academic articles. You will also occasionally address the rhetoric of campaigns outside of their chosen industry. Posts will address a variety of topics (and varying degrees of "meta-ness"). Below, you'll see two typical blog post prompts, but full instructions for each week are included in the syllabus.

Sample post prompts:

1. The Weekly Round-up: Write a comparison/contrast post of the three social media campaigns you're following. What did each organization (or individual, etc.) do on social media this week? What was especially interesting (or not)? What venues did they employ? What rhetorical appeals did they rely upon? What audiences do you think they were attempting to reach, and toward what goals or purposes? How can you tell? You should provide in-depth analysis for at least one specific example from each individual or organization, and you should include images and/or screen shots when you are analyzing visuals. Finally, you should note whether there was a stand out among the three for best (or worst) this week. NOTE: Weekly round-ups vary in length, but a good average to aim for is between 1,000 and 1,400 words.

2. Choose a social media post (a FB update or link, a Tweet, a "pin," etc.) from your "least effective" organization. Describe it and, being as specific as possible, and then perform a rhetorical analysis of the post. You might consider the following questions to get your mind moving in the right direction: What is the purpose of this social media campaign overall? How does this post fit in? What surprises, perplexes, or interests you about this post? Is it more image driven or word driven? What clues here hint at its intended audience and the advertiser's assumptions about that audience? Does the ad contain a logo or slogan? If so, in what way does it contribute? What kinds of rhetorical appeals are used in an attempt to persuade the consumer? Is it ultimately effective?

\section{Logistics}

One free, easy to use blog program that I would highly recommend is Wordpress, as this 
platform is incredibly versatile and could be potentially useful to you in the future. You will find Wordpress tutorial videos posted on our class website, along with suggestions for getting started. If you choose to use another platform, that's okay too, though. And if you're particularly web savvy and want to create a web site for your blog, or you choose to customize your blog, that's great, but if not, don't worry-you're only being graded on the writing.

\section{Assignment Part 2: Semester Project Prompt \#consultants \#socialmediarockstars \#thesearegoingtobeawesome}

\section{Learning Goals}

- Convey an understanding of social media marketing principles

- Find and explore resources, read them critically, use them successfully as support, and cite them correctly

- Ask sound questions and think analytically, critically examining beliefs and assumptions

- Manage time, schedule, and resources effectively

- Work collaboratively

- Use technology as a tool for both communication and credibility

- Develop, support, position, reposition, and present a sound argument, while anticipating and addressing questions and counterarguments

- Utilize rhetorical principles as a way to tailor communication for purpose and genre, audience, structure, tone, level of formality, and document design

- Write and revise significantly through multiple drafts, considering outside feedback

- Edit and proofread carefully to ensure the presentation of an error-free final product

\section{Overview}

Your final project draws together many of the skills and concepts you've been building throughout the semester and asks you to implement not only your content knowledge, but also your critical thinking and writing skills in a complex, multi-step assignment. We will work through this project in stages, discussing, brainstorming, writing, considering feedback, and revising. Further, the work you will complete for this project utilizes, builds on, and asks you to reconfigure many of the smaller writing assignments you've completed, both on your blog and in class.

\section{The Scenario}

Congratulations! Based on your insightful and engaging blog, as well as the industryspecific expertise you've demonstrated, you've been hired as a consultant with Social Media Rock Stars, a start-up social media marketing firm. Details on your first big project are below. 
- message

From: Taylor "Your Boss" Taylorson

Date: Tue, October 15, 2016 at 10:46 AM

Subject: Info for upcoming client project/presentation

To: You

Greetings -

I'm writing with good news! One of the organizations/individuals whose social media presence you've been tracking (amazing coincidence, no?) has put out a call for a consultant to critique their current campaign and implement a new, more effective social media marketing plan. You're in charge of the proposal and presentation that will convince them that we know social media, their field, and what works in it.

One complication is that the company calling for presentations/proposals has had so little success with social media that they're not even $100 \%$ convinced using it is worthwhile. So, you're not only selling yourself and your ideas, but you also have to make a case for why this type of marketing is so crucial in their field. Also, remember that you are an expert, meaning you are doing the work your clients can't/won't do, like deciphering complex material that could potentially help them. To that end, you should include some scholarly research (and it would be tough to be convincing in this realm with fewer than 10-12 sources). This might come in the form of examining the psychology of buyers, taking a more in-depth look at industry economics, or even looking at interesting cases or studies that the organization might reframe as content for their social media outreach. What you research is up to you and will be determined by your industry/field, but you must make a convincing, supported argument for the organization to move forward with you as their consultant. (Your research will be a combination of scholarly and popular sources, and it will also call on individual Facebook posts, Tweets, etc.)

The proposal isn't due for another two months, but obviously you'll want to get started on this ASAP. As you plan, you should consider the following deliverables:

- Annotated Bibliography -I'd like you to submit to me well before to the presentation an annotated bibliography of at least five sources you plan to use in your proposal. We want to show our expertise as well as our research ability, so this should include at least four scholarly sources. The annotated bibliography will give you an opportunity to begin to examine the sources you've found for your proposal for relevance and validity, and map out your project plan in terms of both your research and the writing. For each source, you should summarize, address credibility issues (of publication, author, bias in writing, etc.), state the article's limitations, and note how this source might contribute to your proposal as a whole. Each annotation should be approximately 100-150 words each. Creating an annotated bibliography requires several critical thinking and writing skills: describing, summarizing, and analyzing, most notably. Examining and evaluating sources is 
difficult work. As you write, you should keep in mind the following questions: What is the author's main point? Is it logical? Does he or she support it? Where did I find this source? Is it from a "legitimate" publication? Is the writing unbiased? Who is the author and what are his or her credentials? What issues or limitations are at play here? What is the overall quality of the writing, as I see it? You will need to have each of your sources cited in MLA format. (See attached sample.)

- Proposal - (Note: You've already written about a lot of this in blog form, so part of the writing here will be rethinking the material for different audiences and purposes.) The proposal will include:

- Cover page

- Executive summary - This will likely be the last thing you write, and it should provide an overview of your arguments and a run-down of the information included in the proposal. (1 paragraph, on its own page)

- Introduction and Background - This section (approximately 3-4 pages):

* introduces you as a consultant, including relevant credentials

* provides a concise statement that signifies your understanding of the company or organization, including their goals, pertinent history, and/or any issues they are working against

* clearly states the purpose of the campaign you are proposing (Is it to sell? To raise donations? To inform? To create a better/different image or brand? To attract a new audience? Some combination of these?)

* provides an audience assessment - who is the organization's current target audience? How can you tell? Is this, in fact, who they should be targeting? Explore the demographics of the audience in the context of the campaign's purpose.

* begins to make a case for your ideas by introducing the ideas in your proposal at large while placing these ideas in a larger context by introducing "conversation partners" who have written about this industry or discipline as well as those who have written about social media marketing. You want to introduce your reader to who they'll be hearing from throughout the proposal as well as demonstrate to the reader that you know the field at large.

- Case for employing social media-Why use social media in this field, for this audience, towards these goals? This section should include outside research (approximately 1-2 pages)

- Competitive research overview - What are other organizations doing effectively (or not) in this field, using specific examples and "mini-analyses" (approximately 3-4 pages) 
- Critique of current campaign - Specifically, what have they have been doing that is not working and why (approximately 2-3 pages)

- Overview of the proposed campaign - An exploration of the social media avenues they should be pursuing and a sampling of status updates, tweets, calls for a response or user-generated content, etc. and why these will be effective. This section should also include research and address potential counterarguments. (anywhere from 4-6 pages; organization up to you, and subheads for readability and images or screenshots are encouraged-be sure to focus on what will be easiest/most effective for the client)

- Works cited-MLA style

*NOTE: page counts are approximate, and are counted by double-spaced pages, although for the final version, you may choose to format/space any way you like.

- Presentation of 8-10 minutes - Organization is up to you, but the presentation should address each element in the proposal and make a strong case for the organization to hire you as a consultant; also, the audience for this presentation will be both high-level and low-level employees in the organization's marketing department, including some who have been managing their current social media work, so diplomacy is key. These are very busy people, so you must stay within the time frame. Also, for the presentation, you will need to use some form of presentation technology (PowerPoint, Keynote, Prezi, etc.).

- Wrap-up email - Finally, be sure to email me and let me know how the presentation goes within a day or two after your presentation. A casual email will be fine, but be sure to be detailed and specific, and address the following questions: What was the process like for this project? How did it evolve over time? How and why did you make your most important decisions? Were they good ones? Were the project and the presentation, in your opinion, ultimately successful? Why or why not? What would you do differently next time? In what ways did this project force you to think critically about social media and argument? Also, please let me know how the collaboration element went (how, specifically, it improved your project, how each team member contributed, and how providing feedback to the rest of your group shaped your own thinking, as well as any issues or concerns you ran into during the collaboration). In this email you should also send me the file or link to your presentation file.

The proposal should, of course, look professional, and I would recommend using screenshots to break up the text and illustrate some of your points. These will probably be particularly relevant in the competitive research overview and your critique of their current campaign.

All of our consultants are really busy right now, so, to help, I'm grouping you and two other colleagues as team. You'll conceptualize the proposed campaign, write the proposal, and present on your own, but as you work through the project, you'll have this team to 
support you and provide feedback (and you'll do the same for them). You should plan to meet with your team several times, and as a group you'll all convene with me at least once to discuss your campaigns and progress. (We will discuss scheduling at our next staff meeting, but in the meantime, I've set up a folder for your team on the department [class] site.)

Remember, you're making an overarching argument here that a.) You're an expert, and b.) You can help this organization. These ideas should guide you ask as you get started and as you write and revise. This is a big project, and the deliverables are obviously going to require multiple drafts, but you're prepared, and I know you'll be professional. Let me know if you have any questions, and good luck!

Taylor

\section{Notes}

\footnotetext{
${ }^{1}$ Several sources were consulted in the construction of this assignment, including Ghnassia and Seabury (2002), Fortuna (2015), Verzosa Hurley and Kimme Hea (2014), Kolb (2015), and Vie (2008).
}

\section{References}

Anson, C. M., \& Moore, J. L. (Eds.). (2017). Appendix A: The Elon statement on writing transfer. In Critical transitions: Writing and the question of transfer. Fort Collins, Colorado: WAC Clearinghouse.

Bass, R., \& Elmendorf, H. (2018). Designing for difficulty: Social pedagogies as a framework for course design. Georgetown University Blog Commons. Retrieved from https://blogs.commons.georgetown.edu/bassr/social-pedagogies/

Bitzer, L. F. (1968). The rhetorical situation. Philosophy \& Rhetoric, 1(1), 1-14.

Bush, J., \& Zuidema, L. A. (2011). Professional writing in the english classroom: Beyond language: The grammar of document design. The English Journal, 100(4), 86-89.

Fortuna, C. (2015). Digital media literacy in a sports, popular culture, and literature course. Journal of Media Literacy Education, 6(3), 81-89.

Ghnassia, V. J. D., \& Seabury, M. B. (2002). Interdisciplinarity and the public sphere. The Journal of General Education, 51(3), 153-172.

Kolb, D. A. (2015). Experiential learning: Experience as the source of learning and 
development. New Jersey: Pearson Education.

Krause, T. (2010). Using simulation to teach project management in the professional writing classroom. The Writing Instructor. Retrieved from http://files.eric.ed.gov/ fulltext/EJ890598.pdf

Shaver, L. (2011). Using key messages to explore rhetoric in professional writing. Journal of Business and Technical Communication, 25 (2), 219-236.

Tuomi-Gröhn, T., \& Engeström, Y. (2003). From transfer to boundary-crossing between school and work as a tool for developing vocational education. In T. Tuomi-Gröhn \& Y. Engeström (Eds.), Between school and work: New perspectives on transfer and boundary-crossing (pp. 1-15). Bingley, UK: Emerald Group Publishing.

Verzosa Hurley, E., \& Kimme Hea, A. C. (2014). The rhetoric of reach: Preparing students for technical communication in the age of social media. Technical Communication Quarterly, 23(1), 55-68. http://doi.org/10.1080/10572252.2014.850854

Vie, S. (2008). Digital divide 2.0: "Generation M" and online social networking sites in the composition classroom. Computers and Composition, 25(1), 9-23. 